\title{
THE ACTION OF MAGNESIUM ON THE HEART
}

\author{
BY \\ P. SZEKELY \\ From the Cardiovascular Department, Newcastle General Hospital, Newcastle-on-Tyne \\ Received May 12, 1945
}

\begin{abstract}
Although it has been repeatedly established both in man and in animal experiments that magnesium has a depressant action on the heart, there is no general agreement about the mechanism of this action, and there are few reports dealing directly with the clinical application of its cardio-inhibitory properties. Zwillinger (1935) studied the effect of magnesium sulphate on paroxysmal tachycardia, auricular fibrillation, flutter, and extrasystolic arrhythmia; the paroxysms of tachycardia stopped immediately after the intravenous administration of the drug; extrasystoles were usually abolished; no effect, however, was noticed in auricular fibrillation and flutter. Rothberger and Zwillinger (1936) showed experimentally that magnesium salts in large doses depress conduction, and depress or abolish abnormal impulse production: they succeeded in combating ventricular tachycardia produced by barium chloride or strophanthin. Miller and van Dellen (1938) conducted cardiographic studies in dogs that had been given magnesium sulphate intravenously, and observed a delay in A-V and intraventricular conduction time. Smith, Winkler, and Hoff (1939) reported a sequence of cardiographic changes in the unanæsthetized dog during continuous intravenous administration of magnesium sulphate. They showed that intra-cardiac conduction was depressed in all its elements. After a transient initial tachycardia, bradycardia appeared, and there was a progressive increase in the $\mathrm{P}-\mathrm{R}$ interval as the concentration increased, until A-V block of various grades and widening of $Q R S$ appeared. If the concentration was raised sufficiently, cardiac arrest resulted. Except for the initial tachycardia, similar results were obtained in cats. In the authors' own words- " the cardiac arrest which always occurs if the magnesium concentration is pushed high enough cannot be explained as the result of this depression of conduction, since in most instances the last beats showed a well defined and vigorous systole. For an adequate explanation of this final arrest it is necessary to assume a more direct toxic action of magnesium on the myocardium itself." Bernstein and Simkin (1939) observed only minor changes in the human cardiogram following the intravenous injection of 10 to 20 c.c. of a 10 per cent solution of magnesium sulphate in both cardiac and non-cardiac subjects. These changes consisted of variations in the amplitude of the QRS and T waves. There were no changes in the heart rate or the P-R interval. Boyd and Scherf (1943) recommended magnesium sulphate as a useful therapeutic procedure in paroxysmal tachycardia; using 20 c.c. of a 20 per cent solution they succeeded in terminating each of eight attacks. In one of the paroxysms reported by Decherd and Herrmann (1944) magnesium sulphate, injected intravenously to measure the circulation time, stopped the tachycardia immediately. In a recent report Pines et al. (1944) produced further evidence of the cardio-inhibitory property of magnesium sulphate, and showed that the addition of magnesium sulphate to the intravenous or intracardiac injection of a lethal dose of mercurial diuretic prevents ventricular fibrillation and death of the dog.
\end{abstract}

\section{Present Investigation}

The 26 cases included in this study were in-patients of the Newcastle General HospitaI under the care of Professor W. E. Hume: they comprise 13 with paroxysmal tachycardia, 9 with auricular fibrillation, 5 of which also showed extrasystoles, and 4 with purely extra- 
systolic arrhythmia. Three of the cases of paroxysmal tachycardia might have been regarded as instances of auricular flutter, but they conform to the definition of paroxysmal tachycardia given recently by Evans (1944). Some of the cases of paroxysmal tachycardia and auricular fibrillation were included in the material of a previous study (Szekely, 1944), but none of the cases analyzed here in detail and none of the cardiograms have been reported before. Ten cases with sinus rhythm were also studied with special reference to the effect of magnesium on the rate, the P-R, QRS, and Q-T intervals. In each instance magnesium sulphate was given intravenously, the dose being 20 c.c. of a 20 per cent solution unless stated otherwise.

Case 1. A woman, aged 67, was admitted to hospital in October, 1942, with congestive heart failure and auricular fibrillation. Treatment with digitalis was started at once (digitaline Nativelle, $1 / 600$ of a grain, six times daily). Four days later, she was found to have paroxysmal tachycardia at a rate of 168 a minute (Fig. 1). Digitalis was discontinued and 10 c.c. of a 20 per cent solution of
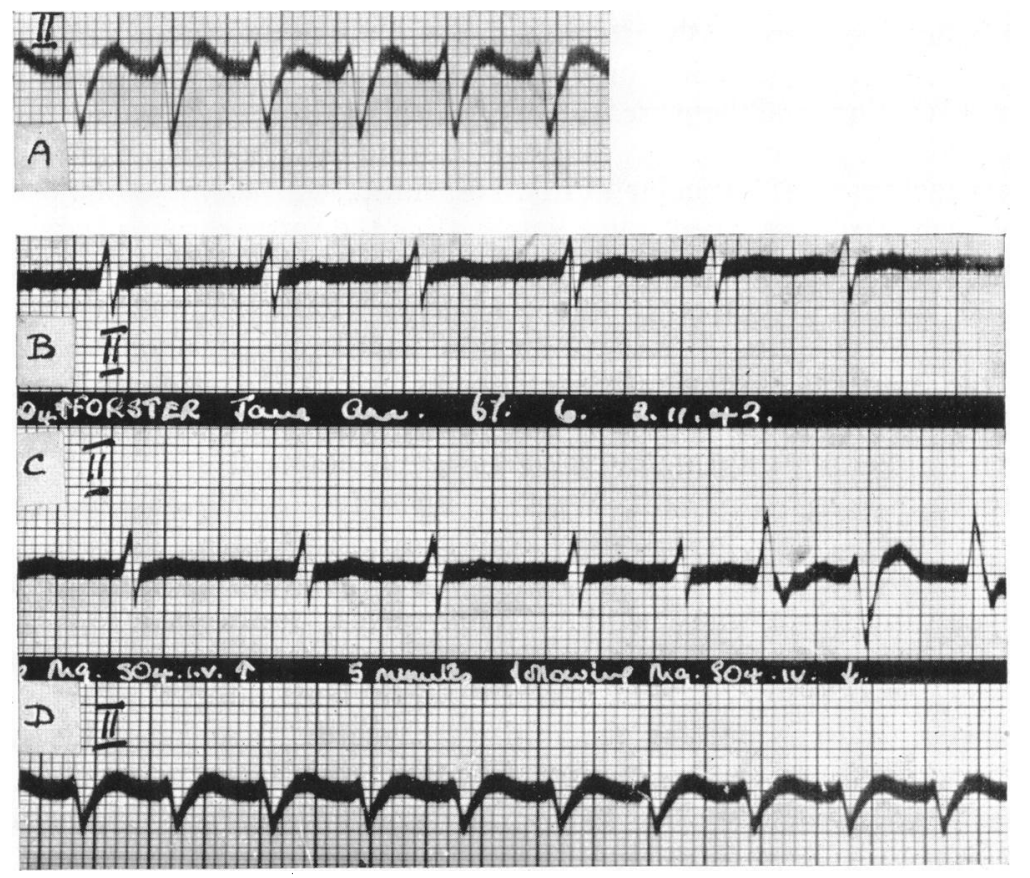

Fig. 1.-Case 1. Paroxysmal tachycardia occurring during auricular fibrillation. (A) Before, (B) Immediately after, (C) 3 minutes after, and (D) 5 minutes after injection of magnesium sulphate. This and subsequent figures have been reduced to five-sixths.

magnesium sulphate were given intravenously. The tracings taken immediately after, and three and five minutes after the injection are reproduced in Fig. 1; they show immediate cessation of the tachycardia and restoration of auricular fibrillation. After three minutes extrasystoles appeared and paroxysmal tachycardia recurred. A second injection of magnesium sulphate, ten minutes later, had the same effect, but this time the tachycardia was arrested for about seven minutes. As the tachycardia recurred and persisted, quinidine sulphate was started by mouth. After three doses each of 5 grains at two-hourly intervals, auricular fibrillation reappeared. Quinidine was then continued, 3 grains daily. Two days later, digitalis was restarted and after two doses of 1/600 of a grain of digitaline Nativelle a rapid regular rhythm developed, presumably paroxysmal tachycardia as before, and the patient died shortly after. Autopsy revealed a moderate degree of diffuse coronary sclerosis with some myocardial fibrosis.

Case 2. A man, aged 59, entered hospital with hypertensive heart failure. He showed the WolffParkinson-White syndrome. The attacks of tachycardia usually lasted for more than twenty-four hours. Intravenous magnesium sulphate terminated one of the paroxysms within five minutes (Fig. 2). As the effect of magnesium is usually immediate (Boyd and Scherf, 1943), it is doubtful whether the disappearance of the tachycardia in this case can be attributed to the drug. 

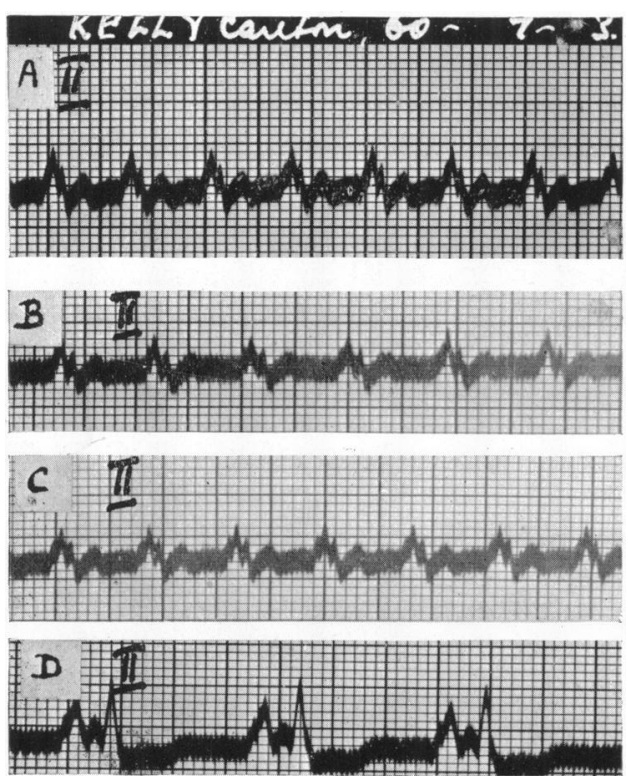

FIG. 2.-Case 2. Paroxysmal tachycardia in case showing Wolff-Parkinson-White syndrome. (A) Before, (B) Immediately after, (C) 2 minutes after magnesium sulphate; no change, and (D) 5 minutes after, showing return of original rhythm.
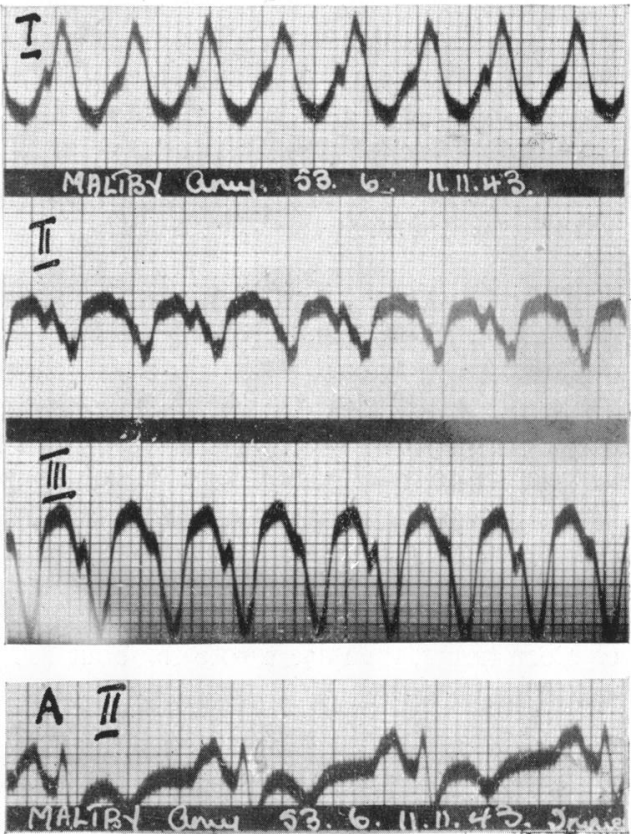

FIG. 3.-Case 3. Mitral stenosis and hypertension. Above, limb leads showing paroxysmal tachycardia, rate 216 a minute. (A) Immediately after magnesium sulphate; sinus rhythm restored.

FIG. 4.-Case 4. (A) Before magnesium injection, shows paroxysmal tachycardia, rate 186 a minute. (B), (C), and (D) Continuous strips of lead II after injection. (G) 12 seconds after (D); described in text. 
Case 3. A woman, aged 53, was admitted complaining of palpitation. She had taken digitalis for a week before admission. The heart rate was rapid and regular, due to paroxysmal tachycardia, probably ventricular in origin, rate 216 a minute (Fig. 3). The paroxysm was terminated by an intravenous injection of magnesium sulphate and sinus rhythm was restored (Fig. 3). In this case, the effect of magnesium was permanent, and the tachycardia did not recur. During normal rhythm the diagnosis of mitral stenosis and hypertension was established. The patient was discharged two weeks later in a satisfactory condition.

Case 4. A man, aged 74, was admitted with hypertensive heart failure. He had a regular rhythm, rate about 100 a minute. As he did not respond to rest and mercurial diuretics, treatment with digitalis was started. After six days he developed a rapid, regular paroxysmal tachycardia, rate 186 a minute (Fig. 4, A), and digitalis was discontinued. The intravenous injection of 10 c.c. of a 20 per cent solution of magnesium sulphate was followed by a transient change in the shape of the ventricular complexes, but there was no appreciable change in the rate. A few hours later, the same dose of magnesium sulphate was repeated and resulted in immediate changes (Fig. 4, B, C, D, G). After a short run of ventricular tachycardia, rate about 125 a minute, complete A-V dissociation appeared-A., 210; V., 38 gradually increasing to 50 . There was variation in the shape of the auricular complexes and alternation of the cycle length. The slow ventricular rate persisted for about eighteen hours, then again rose to about 180 a minute. The patient died shortly after. No autopsy was done.

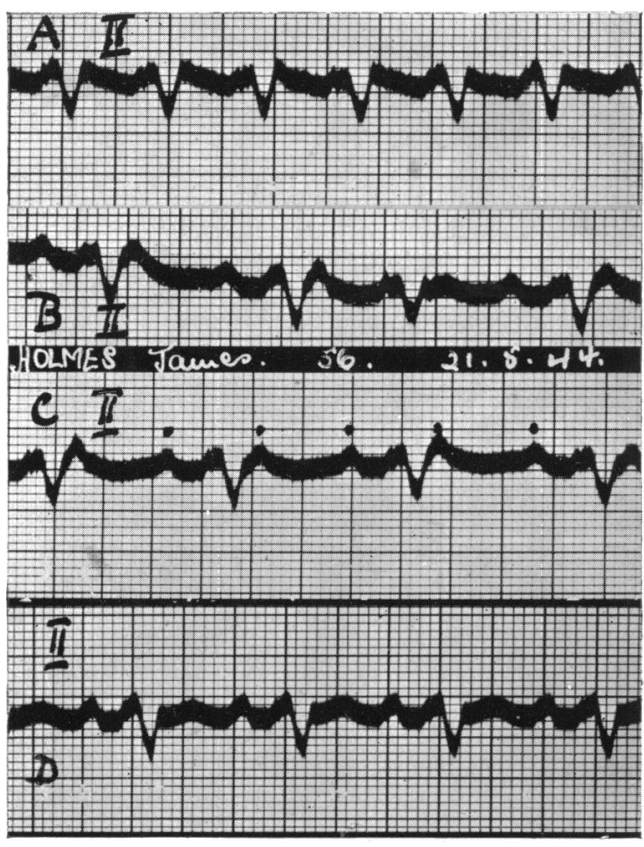

Fig. 5.-Case 5. (A) Paroxysmal tachycardia and probably $2: 1$ A-V block. (B) Immediately after injection of magnesium; $2: 1 \mathrm{~A}-\mathrm{V}$ block, auricular rate 170 . (C) 3 minutes after; no change. (D) 20 minutes after ; sinus rhythm with original bundle branch block pattern.
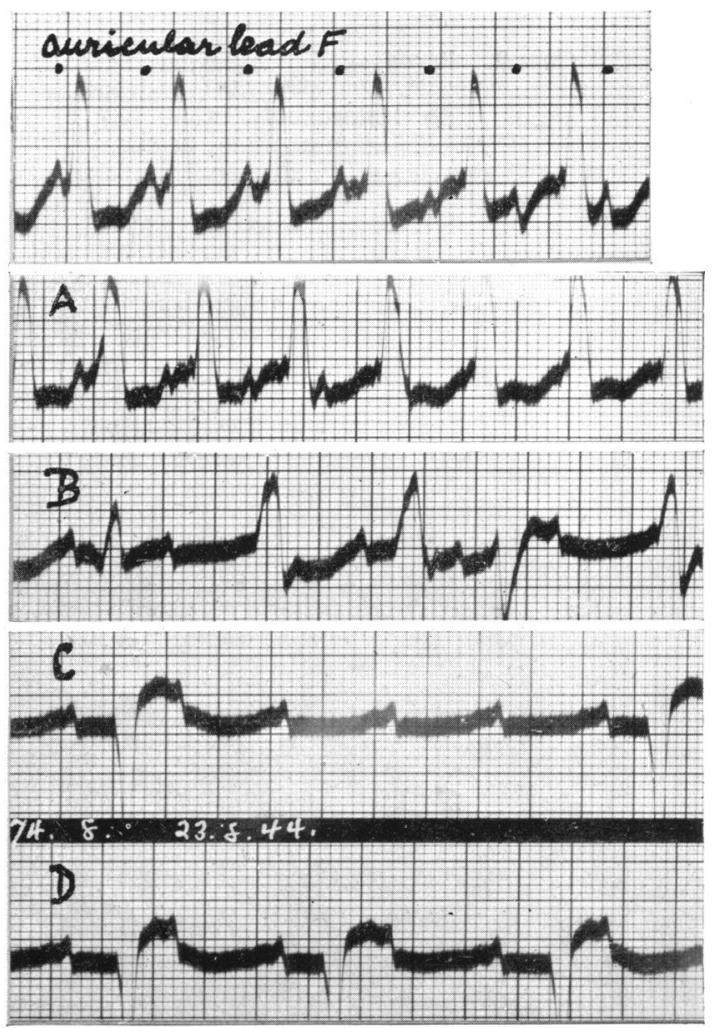

Fig. 6.-Case 6. Auricular chest lead. Upper tracing. - Paroxysmal tachycardia with A-V block, dots denote $P$ waves ; auricular rate 170 , ventricular rate slightly slower. (A) During injection of magnesium; auricular rate 186 . (B) Immediately after; auricular rate 170, multifocal ventricular beats. (C) 2 minutes after; auricular rate 150 , ventricular rate 30 . (D) 3 minutes after; auricular rate 150 , ventricular rate 75 . 
Case 5. A man, aged 56, was admitted to hospital on April 28, 1944, with hypertensive heart failure. He had a large heart, triple rhythm, and left bundle branch block. Treated with digitalis and mercurial diuretics, he improved, but on May 25 his heart rate increased suddenly-paroxysmal tachycardia with 2 to $1 \mathrm{~A}-\mathrm{V}$ dissociation; auricular rate 340 a minute (Fig. 5, A). Digitalis was discontinued, and the magnesium sulphate was given intravenously. The tracings taken immediately and at intervals of three and five minutes after the injection showed $2: 1 \mathrm{~A}-\mathrm{V}$ block, auricular rate about 170 a minute (Fig. 5, B, C). The tracing in Fig. 5, D, taken twenty minutes after the injection, shows sinus rhythm and the original bundle branch block pattern. There was no recurrence of the tachycardia and the patient was discharged ten days later in a satisfactory condition.

Case 6. A man, aged 74, entered the hospital with congestive heart failure. He had an enlarged heart with normal blood pressure and regular rhythm. Four days after admission the heart rate suddenly increased and Fig. 6 showed paroxysmal tachycardia with A-V dissociation, which is clearly shown in the auricular lead. The auricular rate was 170 a minute and the ventricular rate slightly slower. The intravenous injection of magnesium sulphate resulted in only slight changes in the auricular rate, but greater changes in the ventricular rate (Fig. 6, A, B, C, D). After a slight initial rise the auricular rate fell to 150 a minute. The ventricular rate fell to about 30 a minute and then rose to 75 a minute, this rate persisting until the death of the patient three days latter. Unfortunately no record was taken before the onset of the tachycardia, so that it is impossible to say what the original rhythm was.

Case 7. A man, aged 23, was first seen in April 1942, and again in November 1944, with mitral stenosis and congestive failure, with normal rhythm. Shortly after admission, paroxysmal tachycardia was recorded, ventricular rate 176 (Fig. 7). Within a few minutes, the deflection of the string changed and lead III, recorded five minutes after the first curve, showed an increased widening of QRS without any change in rate (Fig. 7, A). Magnesium sulphate was then given intravenously; a curve taken immediately showed no change (Fig. 7, B); after $1 \frac{1}{2}$ minutes the QRS returned to its original form (Fig. 7, C); after $2 \frac{1}{2}$ minutes sinus rhythm was recorded (Fig. 7, D), and there was no recurrence of tachycardia up to the patient's death six days later. No autopsy was obtained.

Case 8. A man, aged 39, had coronary occlusion with hemiplegia and Streptococcus viridans septi-
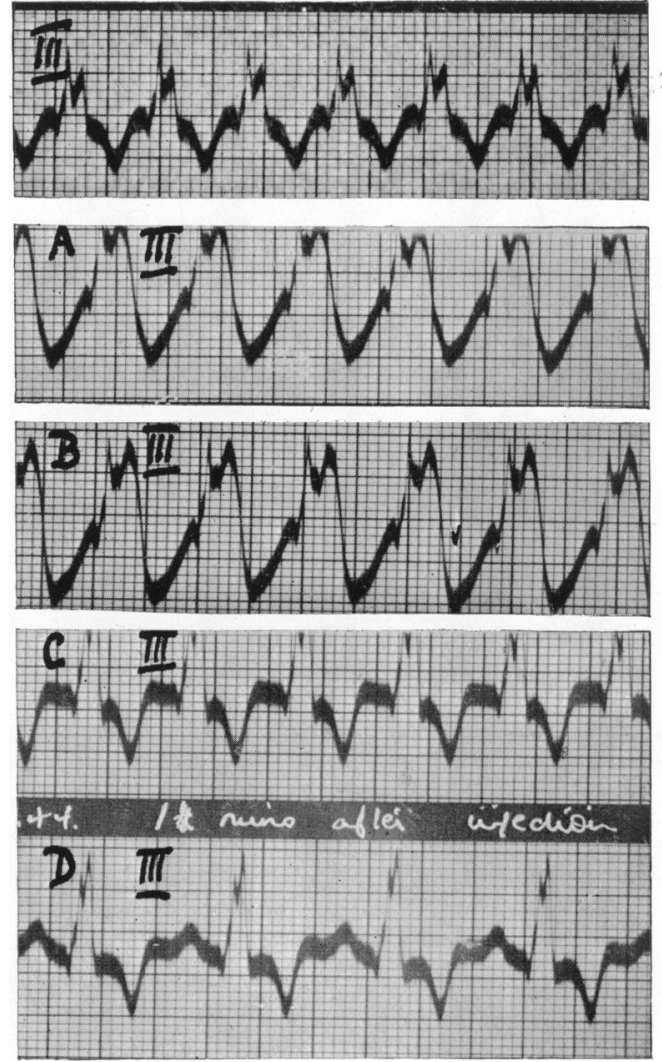

FIG. 7.-Case 7. Lead III. Upper tracing ; paroxysmal tachycardia, ventricular rate 176 ; probably 2:1 A-V block. (A) Spontaneous change of QRS. (B) Immediately after magnesium; no . change. (C) $1 \frac{1}{2}$ minutes after; QRS returned to original form. (D) $2 \frac{1}{2}$ minutes after; sinus rhythm restored. cæmia. His initial cardiogram showed changes characteristic of anterior myocardial infarction. He died two months after admission and the diagnosis was confirmed at autopsy. Five days prior to death the rhythm changed to auricular fibrillation. About four hours later, a regular tachycardia, auricular rate 500 a minute, was recorded (Fig. 8). Intravenous injection of magnesium sulphate slowed the auricular rate to 300 and the ventricular rate to 150 a minute (Fig. 8, A, B, C). The original rate recurred the following day and persisted until the patient's death.

Case 9. A woman, aged 62, was admitted in 1944, with hypertensive heart failure and left hemiplegia. The cardiogram showed paroxysmal tachycardia with 2:1 A-V block (Fig. 9, A), auricular rate 320 a minute. Magnesium sulphate intravenously increased the A-V block (Fig. 9, C); $4: 1 \mathrm{~A}-\mathrm{V}$ block persisted for an hour, when the original 2:1 block reappeared and persisted until death three days later. Autopsy refused. 
Case 10. A woman, aged 51, had been seen for several years with rheumatic heart disease and auricular fibrillation. She died in hospital and autopsy confirmed the diagnosis. During her last three years she had practically never been without digitalis. On one occasion extrasystolic bigeminy was recorded (Fig. 10, A). After an injection of magnesium sulphate the extrasystoles were not completely abolished but their voltage was reduced (Fig. 10, B and C); the voltage of the normal ventricular complex was unaffected. This demonstrates the depressant action of magnesium on ectopic centres, while the normal complexes remain unchanged. The duration of this effect was not observed.
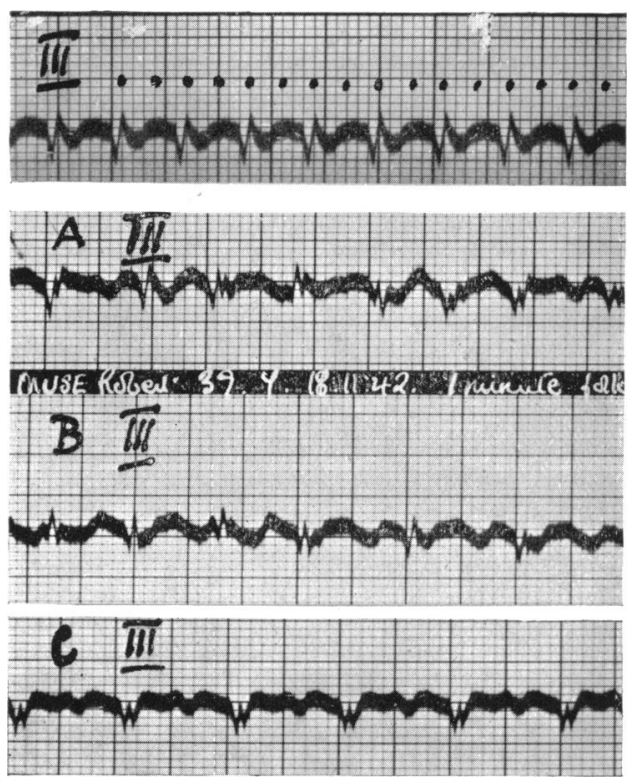

FIG. 8.-Case 8. Coronary occlusion. Upper tracing. Auricular tachycardia with $2: 1$ block, auricular rate 500 . (A) 1 minute after magnesium ; variable A-V block. (B) 2 minutes after ; auricular rate 300 , variable A-V block. (C) 4 minutes after; auricular rate $300,2: 1 \mathrm{~A}-\mathrm{V}$ block.

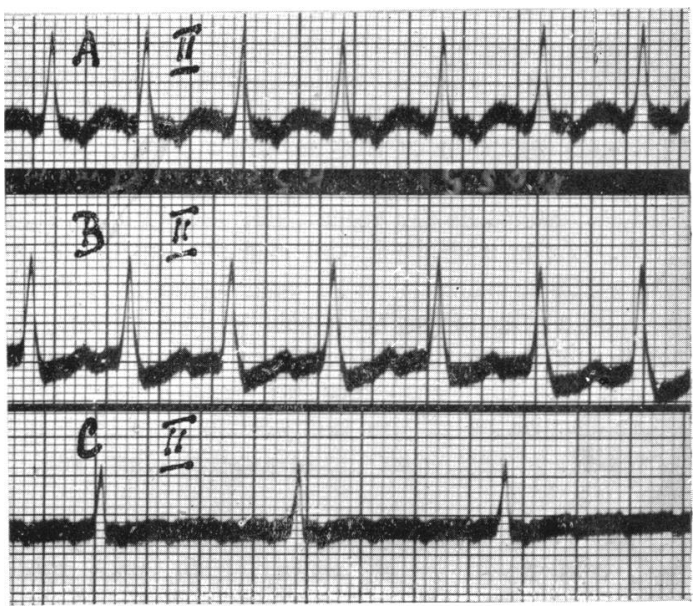

FIG. 9.-Case 9. (A) Auricular tachycardia with $2: 1$ block, auricular rate 320. (B) During injection of magnesium ; change in shape of auricular waves. (C) Immediately after; ventricular rate halved.

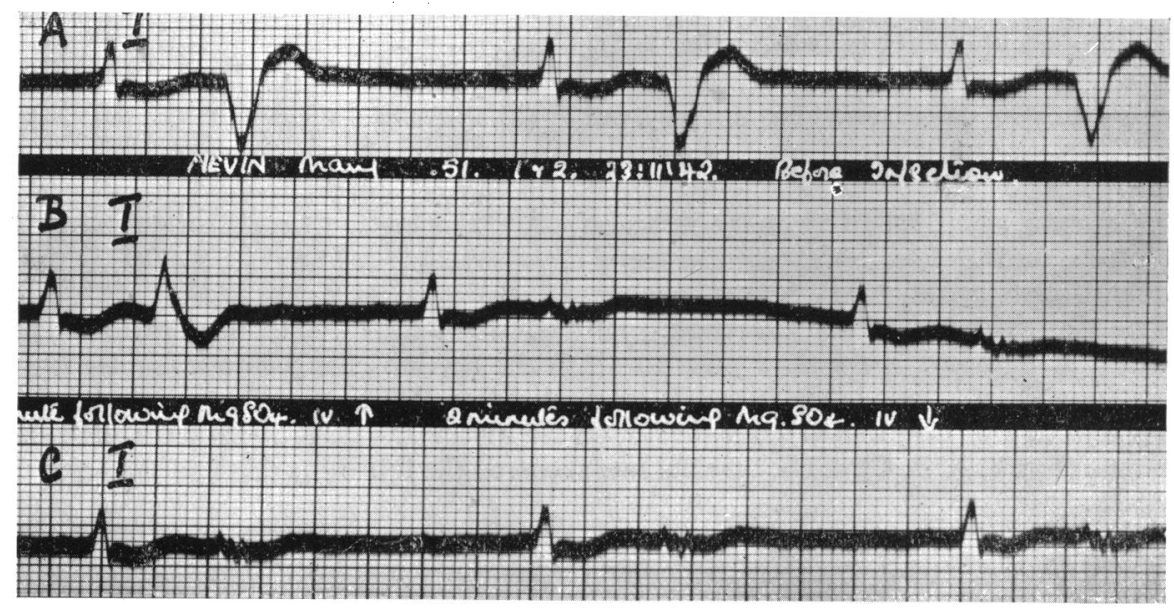

FIG. 10.-Case 10. (A) Auricular fibrillation and extrasystolic bigeminy in a digitalized patient. (B) and (C) 1 and 2 minutes respectively, after injection of magnesium. Decrease in voltage of extrasystolic beat. Voltage of normal com lex remains unchanged. 
Case 11. A woman, aged 77, was admitted in 1944 with congestive heart failure. The rhythm was regular. Though there was no history of cardiac pain, the low blood pressure and the chest lead cardiogram suggested anterior myocardial infarction. She was given digitalis and mercurial diuretics, and improved; after three weeks treatment extrasystolic bigeminy and $2: 1 \mathrm{~A}-\mathrm{V}$ block was recorded (Fig. 11). After an intravenous injection of magnesium sulphate the extrasystoles were completely abolished, and did not recur; the patient was discharged ten days later in a satisfactory condition.

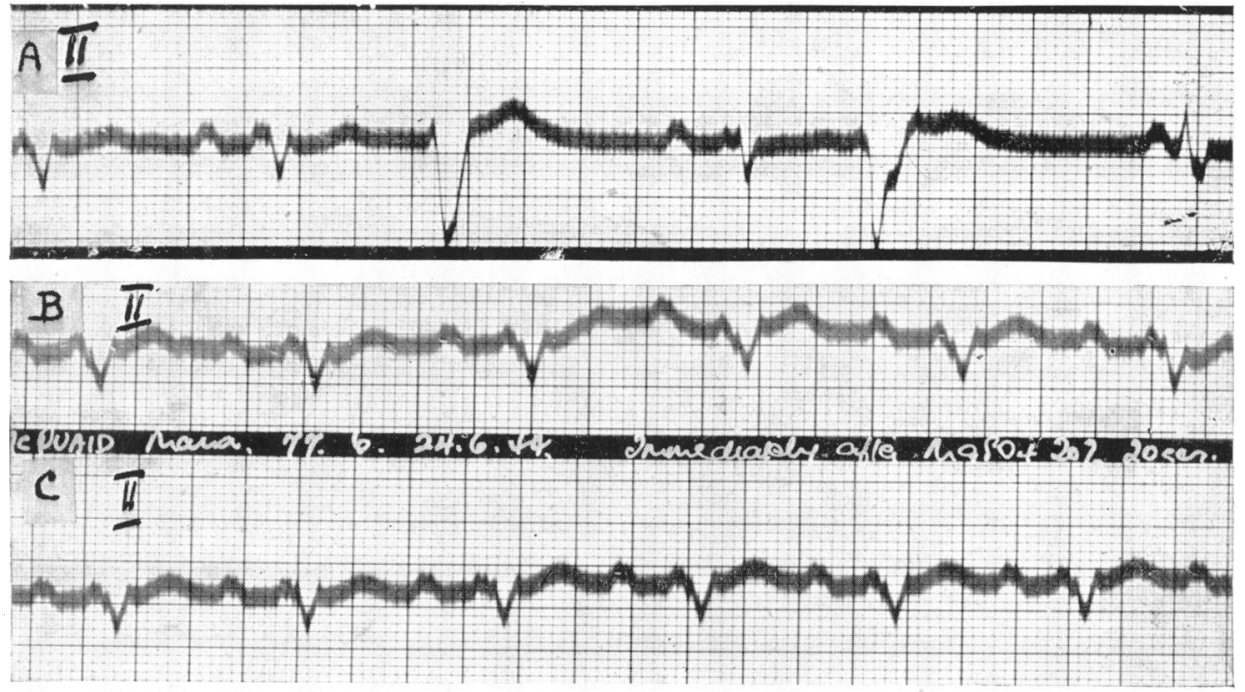

FIG. 11.-Case 11. (A) Extrasystolic bigeminy and 2:1 A-V block due to digitalis. (B) Immediately after magnesium and (C) 2 minutes after : sinus rhythm with prolonged P-R; extrasystoles abolished.

\section{Discussion}

The findings confirm the views of previous investigators that magnesium has a depressant action on the heart muscle. The results obtained in paroxysmal tachycardia are summarized in Table I. Of 13 cases, 9 were affected by magnesium, and in 5 of them (Cases 2, 3, 5, 6, and 7) the effect appeared to be lasting; in 4 of them sinus rhythm was restored, and in the fifth case, though the ventricular rate was much reduced, the auricular rate was only slightly slowed, and the A-V dissociation, originally present, persisted. In 4 (Cases 1, 4, 8,

TABLE I

The Effect of Magnesium on Paroxysmal Tachycardia

\begin{tabular}{|c|c|c|c|c|c|}
\hline Case Number & $\begin{array}{l}\text { Underlying } \\
\text { heart disease }\end{array}$ & Auricular rate & Ventricular rate & $\begin{array}{c}\text { Duration of } \\
\text { effect }\end{array}$ & $\begin{array}{l}\text { Rhythm after } \\
\text { injection of } \\
\text { magnesium }\end{array}$ \\
\hline 1 (Fig. 1) & $\begin{array}{l}\text { Coronary } \\
\text { sclerosis }\end{array}$ & $?$ & Decreased & 3 and 7 minutes & $\begin{array}{c}\text { Auricular fibrilla- } \\
\text { tion }\end{array}$ \\
\hline $\begin{array}{l}2 \text { (Fig. 2) } \\
3 \text { (Fig. 3) }\end{array}$ & $\begin{array}{l}\text { Hypertension } \\
\text { Mitral stenosis } \\
\text { and hyper- } \\
\text { tension }\end{array}$ & $\begin{array}{l}\text { Decreased } \\
\text { Decreased }\end{array}$ & $\begin{array}{l}\text { Decreased } \\
\text { Decreased }\end{array}$ & $\begin{array}{l}\text { Lasting } \\
\text { Lasting }\end{array}$ & $\begin{array}{l}\text { Sinus rhythm } \\
\text { Sinus rhythm }\end{array}$ \\
\hline $\begin{array}{l}4 \text { (Fig. 4) } \\
5 \text { (Fig. 5) } \\
6 \text { (Fig. 6) }\end{array}$ & $\begin{array}{l}\text { Hypertension } \\
\text { Hypertension } \\
\text { Coronary } \\
\text { sclerosis }\end{array}$ & $\begin{array}{l}\text { Increased ? } \\
\text { Decreased } \\
\text { Decreased }\end{array}$ & $\begin{array}{l}\text { Decreased } \\
\text { Decreased } \\
\text { Decreased }\end{array}$ & $\begin{array}{l}18 \text { hours } \\
\text { Lasting } \\
\text { Lasting }\end{array}$ & $\begin{array}{l}\text { A-V block } \\
\text { Sinus rhythm } \\
\text { A-V block }\end{array}$ \\
\hline $\begin{array}{l}7 \text { (Fig. 7) } \\
8 \text { (Fig. 8) }\end{array}$ & $\begin{array}{l}\text { Mitral stenosis } \\
\text { Coronary } \\
\text { thrombosis }\end{array}$ & $\begin{array}{l}\text { Decreased } \\
\text { Decreased }\end{array}$ & $\begin{array}{l}\text { Decreased } \\
\text { Decreased }\end{array}$ & $\begin{array}{l}\text { Lasting } \\
24 \text { hours }\end{array}$ & $\begin{array}{l}\text { Sinus rhythm } \\
2: 1 \mathrm{~A}-\mathrm{V} \text { block }\end{array}$ \\
\hline $\begin{array}{l}9 \text { (Fig. 9) } \\
12 \\
13 \\
14\end{array}$ & $\begin{array}{l}\text { Hypertension } \\
\text { Nil } \\
\text { Nil } \\
\text { Mitral and }\end{array}$ & $\begin{array}{l}\text { Unchanged } \\
\text { Unchanged } \\
\text { Unchanged } \\
\text { Unchanged }\end{array}$ & $\begin{array}{l}\text { Decreased } \\
\text { Unchanged } \\
\text { Unchanged } \\
\text { Unchanged }\end{array}$ & $\begin{array}{r}1 \text { hour } \\
- \\
-\end{array}$ & $\begin{array}{l}4: 1 \text { A-V block } \\
\text { Unchanged } \\
\text { Unchanged } \\
\text { Unchanged }\end{array}$ \\
\hline 15 & Nil & Unchanged & Unchanged & - & Unchanged \\
\hline
\end{tabular}


and 9) the effect was transient, ranging from three minutes to twenty-four hours. In Case 1 the basic rhythm was auricular fibrillation, and this recurred both times the tachycardia was terminated by magnesium. In Case 4, A-V dissociation was present before magnesium was given; after the injection, the auricular rate appeared to be quicker, and there was a marked alternation of the cycle length; the ventricular rate showed a fall. In Cases 8 and 9 the injection resulted in a temporary increase in the A-V block. Magnesium failed to produce any changes in rhythm in the following 4 cases. A male, aged 63 , with nodal tachycardia and no underlying structural disease in the heart, whose tachycardia responded to carotid sinus pressure. A male, aged 36, with auricular tachycardia but no structural disease of the heart, whose tachycardia was terminated by digitalis. A female, aged 17, with mitral stenosis and aortic regurgitation, but free from cardiac enlargement or failure; paroxysmal auricular tachycardia stopped after oral digitalization. A male, aged 50, who had auricular tachycardia with 2:1 A-V block, emphysema, and chronic bronchitis; digitalis first resulted in an increase of the A-V block, and later the tachycardia was replaced by sinus rhythm. Clinically, the interesting feature was the presence of advanced heart disease usually with congestive heart failure in the cases that responded to magnesium, even if the effect was a temporary one, and the absence of these findings in the cases that failed to respond to magnesium. Three of the latter showed no evidence of structural heart disease, and in the fourth there were no signs of heart failure though the heart showed structural changes. The significance of this observation is uncertain as yet, but the question may be usefully discussed in relation to the cardiac action of potassium. Though there is some evidence that potassium may be antagonistic to magnesium (Hirschfelder, 1929; Rothberger and Zwillinger, 1936), there are numerous reports (Ringer, 1882; Sampson and Anderson, 1930; Wiggers, 1930; Winkler, Hoff, and Smith, 1938; Thomson, 1939; Stewart and Smith, 1941; Keith, Osterberg, and Burchell, 1942; Finch and Marchand, 1943; Sampson, Alberton, and Kondo, 1943; Keith, Burchell, and Baggenstoss, 1944) suggesting that the cardio-inhibitory action of potassium is in many respects strikingly similar to that of magnesium. Further, it has been shown that the potassium content of the heart muscle of patients dying of congestive heart failure is diminished (Harrison, Pilcher, and Ewing, 1930; Sampson and Anderson, 1930).

Potassium salts have been used to abolish paroxysmal tachycardia and ectopic beats (Sampson and Anderson, 1930), and it has been suggested that potassium is more effective in this respect when the heart muscle is damaged than when it is healthy. This is ascribed to the low potassium content of the myocardium in heart failure. It is possible that the effect of magnesium in paroxysmal tachycardia depends similarly on the magnesium content of the heart muscle.

Sampson and Anderson (1930, 1932) and Sampson, Alberton, and Kondo (1943) showed that ectopic beats caused by digitalis could always be abolished by potassium, whereas other forms of ectopic beat responded less frequently. There is a loss of potassium from the heart muscle in digitalis intoxication (Sampson, Alberton, and Kondo, 1943). Like potassium, magnesium may be effective in digitalis intoxication (Zwillinger, 1935), and it may be more effective in abolishing ectopic beats due to digitalis than those otherwise caused (Zwillinger, 1935; Herles, 1937; Boyd and Scherf, 1943). The findings given in Table II suggest that magnesium is more likely to affect extrasystoles due to digitalis than other varieties. However, reports dealing with the relation between magnesium and digitalis are contradictory, for Miller and van Dellen (1941) found that magnesium did not counteract digitalis intoxication in dogs. Neither potassium nor magnesium has any effect on the rhythm in auricular fibrillation.

The action of magnesium on the heart has been explained as due to a depression of the cardiac nervous mechanism resulting in loss of tone (Matthews and Brooks, 1910), to a vagal effect, and to a direct effect on conduction (van Dellen and Miller, 1939). Smith, Winkler, and Hoff (1939) maintain that magnesium depresses the S-A, A-V, and intraventricular conduction. Pines et al. (1944) observed disturbances of A-V and intraventricular conduction from large doses of magnesium, but with smaller doses they were able to abolish ventricular fibrillation due to mercurial diuretics without affecting conduction. These findings suggest that magnesium depresses ectopic centres more than the normal conducting system, but that both are depressed by large enough doses. 
To gain more information on the action of magnesium upon the conducting system, 10 cases with sinus rhythm were studied. In 5 of them the cardiogram was normal, and in 5 it showed $T$ wave changes. In each case the limb leads were first recorded, and then usually lead II, immediately after the injection of 20 c.c. of a 20 per cent solution of magnesium sulphate, and two minutes later. Besides minor alterations in the rate in 4 cases, and the appearance of ventricular extrasystoles in 1, no changes were observed. These results are in agreement with those of Bernstein and Simkin (1939) who studied the effect of magnesium on the human

TABLE II

The Effect of Magnesium on Extrasystolic Arrhythmia

\begin{tabular}{|c|c|c|c|c|}
\hline Case Number & Underlying heart disease & $\begin{array}{l}\text { Cause of extra- } \\
\text { systoles }\end{array}$ & Effect & $\begin{array}{c}\text { Duration of } \\
\text { effect }\end{array}$ \\
\hline $\begin{array}{l}10 \text { (Fig. 10) } \\
11 \text { (Fig. 11) } \\
16 \\
17\end{array}$ & $\begin{array}{l}\text { Mitral stenosis } \\
\text { Coronary thrombosis } \\
\text { Hypertension } \\
\text { Mitral stenosis }\end{array}$ & $\begin{array}{l}\text { Digitalis } \\
\text { Digitalis } \\
\text { Digitalis } \\
\text { Digitalis }\end{array}$ & $\begin{array}{l}\text { Decrease in voltage } \\
\text { Extrasystoles abolished } \\
\text { Extrasystoles abolished } \\
\text { Change in shape of extra- } \\
\text { systoles }\end{array}$ & $\begin{array}{l}\text { Unknown } \\
\text { Lasting } \\
\text { Ten minutes } \\
\text { Unknown }\end{array}$ \\
\hline $\begin{array}{l}18 \\
19 \\
20 \\
21 \\
22\end{array}$ & $\begin{array}{l}\text { Mitral stenosis } \\
\text { Mitral stenosis } \\
\text { Nil } \\
\text { Coronary thrombosis } \\
\text { Mitral stenosis }\end{array}$ & $\begin{array}{l}\text { Digitalis } \\
\text { Spontaneous } \\
\text { Spontaneous } \\
\text { Spontaneous } \\
\text { Spontaneous }\end{array}$ & $\begin{array}{l}\text { Trigeminy } \\
\text { Nil } \\
\text { Nil } \\
\text { Nil } \\
\text { Nil }\end{array}$ & $\begin{array}{c}\text { Few minutes } \\
\text { 二 } \\
=\end{array}$ \\
\hline
\end{tabular}

heart in normal cases and in those suffering from various forms of heart disease, and found that magnesium had no effect on the normal conductive system. The appearance of extrasystoles is a paradoxical effect which has also been noticed by others (Miller and van Dellen, 1941; Boyd and Scherf, 1943).

The intravenous administration of magnesium sulphate, in doses up to 20 c.c. of a 20 per cent solution, is a safe procedure and we have seen no untoward effect from it. It causes an unpleasant but transient feeling of intense heat due to a vasodilator action. Though several patients in this series died, the death was unrelated to magnesium sulphate; it was due in every case to the heart failure and condition of the heart that initiated the attack. The time interval between the giving of magnesium sulphate and death ranged from twenty hours to three months. The normal magnesium content of the serum is 2 to $3 \mathrm{mg}$. per 100 c.c. According to Goodman and Gilman (1943), the kidneys excrete magnesium so rapidly that the oral ingestion of magnesium salts results in only a slight rise in the serum magnesium. It is to be expected, therefore, that the serum magnesium, following a single intravenous injection of magnesium sulphate, will return very quickly to the original level. However, by continuous intravenous injection, Smith, Winkler, and Hoff (1939) were able to raise considerably the serum magnesium level. It is generally agreed that the excretion of magnesium is decreased, and correspondingly the serum magnesium increased in patients with renal failure (Hirschfelder and Haury, 1934; Brookfield, 1937; Haury, 1942; Winkler, Smith, and Hoff, 1942). Rubin and Rappaport (1941) warned against the possible danger of administering magnesium to anuric patients, and Hirschfelder and Haury (1934) concluded that hyper-magnesæmia was an important causal factor in many cases of so-called uræmic coma. One should be cautious, therefore, in giving magnesium to patients with renal failure.

\section{Summary AND Conclusions}

The effect of intravenous injections of magnesium sulphate, 20 c.c. of a 20 per cent solution on the human electrocardiogram was studied in cases with sinus rhythm, paroxysmal tachycardia, extrasystolic arrhythmia, and auricular fibrillation.

It was found to have no significant effect on the normal conducting system, and it produced only minor changes in the normal cardiogram.

Out of 13 cases of paroxysmal tachycardia 9 were affected by magnesium sulphate; in 5 the effect was lasting, and in 4 only temporary, i.e. from three minutes to twentyfour hours. In 4 sinus rhythm was restored, in 1 the tachycardia was replaced by the original 
rhythm of auricular fibrillation. In the remaining 4 cases variable degrees of A-V block appeared. A dose of magnesium sulphate that has no appreciable effect on the normal conducting system, may depress impulse production in heterotopic centres. In increased myocardial irritability all parts of the conducting system may be depressed. The data presented justify the use of magnesium sulphate as a therapeutic agent in paroxysmal tachycardia. The intravenous administration of magnesium sulphate is a safe procedure, but its effect may be only tem porary.

Extrasystoles caused by full digitalization were either completely abolished or altered by magnesium, while extrasystoles from other causes were not affected by it. Further investigation of the relationship between magnesium and digitalis is required.

Auricular fibrillation was not affected by magnesium.

The conclusions reached apply only to the human heart and to doses of magnesium sulphate specified. The results of animal experiments are not directly comparable.

I am indebted to Professor Hume for his helpful criticism and advice. I also wish to thank Dr. William Evans for his help and suggestions, Dr. I. E. McCracken, Medical Officer of Health, Newcastle-on-Tyne, and Dr. G. Hurrell, Medical Superintendent, Newcastle General Hospital, for facilities provided, and the Editors of this Journal for their help in reducing and rearranging the paper.

\section{REFERENCES}

Bernstein, M., and Simkin, S. (1939). J. Lab. Clin. Med., 25, 131.

Boyd, L. J., and Scherf, D. (1943). Amer. J. med. Sci., 206, 43.

Brookfield, R. W. (1937). Quart. J. Med., 6, 87.

Castleden, L. J. M. (1941). Brit. med. J., 1, 7.

Decherd, G. M., and Herrmann, G. R. (1944). Amer. Heart J., $28,457$.

van Dellen, T. R., and Miller, J. R. (1939). J. Lab. Clin. Med., 24, 840.

Evans, W. (1944). Brit. Heart J., 6, 221.

Finch, C. A., and Marchand, J. F. (1943). Amer. J. med. Sci., 206, 507. Goodman, L., and Gilman, A., (1943). The Pharmacological Basis of Therapeutics, MacMillan and Co.,

Harrison, T. R., Pilcher, C., and Ewing, G. (1930). J. Clin. Investigation, 8, 323.

Haury, V. G. (1942). J. Lab. Clin. Med., 27, 1361.

Herles, F. (1937). Unpublished data.

Hirschfelder, A. D. (1929). J. Pharmacol. Exper. Therap., 37, 399.

-, and Haury, V. G. (1934). J. Amer. med. Ass., 102, 1138.

Keith, N. M., Osterberg, A. E., and Burchell, H. B. (1942). Proc. Staff. Meet. Mayo Clin., $17,49$.

, Burchell, H. B., and Baggenstoss, A. H. (1944). Amer. Heart J., 27, 817.

Matthews, S. A., and Brooks, C. (1910). Quoted by Miller and van Dellen.

Miller, J. R., and van Dellen, T. R. (1938). J. Lab. Clin. Med., 23, 914.

- , (1941). Ibid., 26, 1116.

Pines, I., Sanabria, A., and Arriens, R. T. H. (1944). Brit. Heart J., 6, 197.

Ringer, S. (1882). Quoted by Castleden.

Rothberger, C. J., and Zwillinger, L. (1936). Arch. Exper. Path. Pharmakol., 181, 301.

Rubin, M. I., and Rappaport, M. (1941). Amer. J. med. Sci., 201, 734.

Sampson, J. J., and Anderson, E. M. (1930). Proc. Soc. Exper. Biol. Med., 28, 163.

- - (1932). J. Amer. med. Ass., 99, 2257.

, Alberton, E. C., and Kondo, B. (1943). Amer. Heart J., 26, 164.

Smith, P. K., Winkler, A. W., and Hoff, H. E. (1939). Amer. J. Physiol., 126, 720.

Stewart, H. J., and Smith, J. J. (1941). Amer. J. med. Sci., 201, 177.

Szekely, P. (1944). Brit. Heart J., 6, 238.

Thomson, W. A. R. (1939). Ibid., 1, 269.

Winkler, A. W., Hoff, H. E., and Smith, P. K. (1938). Amer. J. Physiol., 124, 478.

, Smith, P. K., and Hoff, H. E. (1942). J. Clin. Investigation, 21, 207.

Zwillinger, L. (1935). Klin. Wchnschr., 14, 1429. 